\title{
Gasoline Engine and Fuels Offering Reduced Fuel Consumption and Emissions: Vehicle Modeling Final Report
}

C. Scott Sluder

Nolan Perry

David E. Smith

August 2020 


\section{DOCUMENT AVAILABILITY}

Reports produced after January 1, 1996, are generally available free via US Department of Energy (DOE) SciTech Connect.

Website www.osti.gov

Reports produced before January 1, 1996, may be purchased by members of the public from the following source:

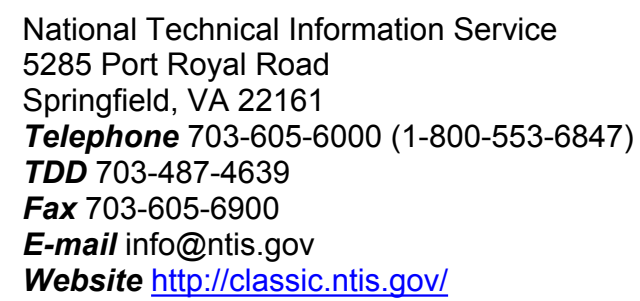

Reports are available to DOE employees, DOE contractors, Energy Technology Data Exchange representatives, and International Nuclear Information System representatives from the following source:

Office of Scientific and Technical Information

PO Box 62

Oak Ridge, TN 37831

Telephone 865-576-8401

Fax 865-576-5728

E-mail reports@osti.gov

Website http://www.osti.gov/contact.html

This report was prepared as an account of work sponsored by an agency of the United States Government. Neither the United States Government nor any agency thereof, nor any of their employees, makes any warranty, express or implied, or assumes any legal liability or responsibility for the accuracy, completeness, or usefulness of any information, apparatus, product, or process disclosed, or represents that its use would not infringe privately owned rights. Reference herein to any specific commercial product, process, or service by trade name, trademark, manufacturer, or otherwise, does not necessarily constitute or imply its endorsement, recommendation, or favoring by the United States Government or any agency thereof. The views and opinions of authors expressed herein do not necessarily state or reflect those of the United States Government or any agency thereof. 


\title{
Energy and Transportation Science Division
}

\section{Gasoline Engine and Fuels Offering Reduced Fuel Consumption and Emissions Vehicle Modeling Final Report}

\author{
Author(s) \\ C. Scott Sluder \\ Nolan Perry \\ David E. Smith
}

Date Published:

August, 2020

Prepared by

OAK RIDGE NATIONAL LABORATORY

Oak Ridge, TN 37831-6283

managed by

UT-BATTELLE, LLC

for the

US DEPARTMENT OF ENERGY

under contract DE-AC05-00OR22725 



\section{CONTENTS}

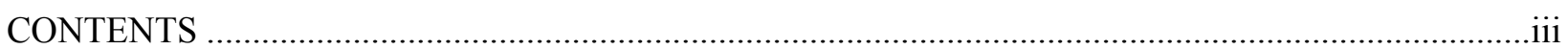

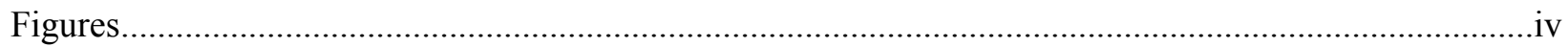

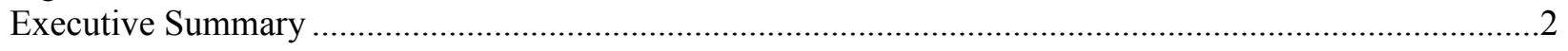



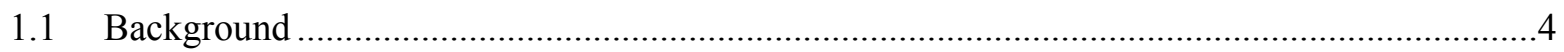

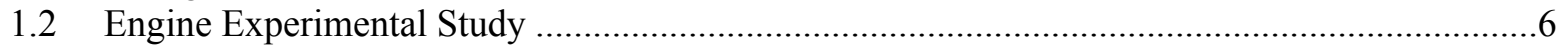

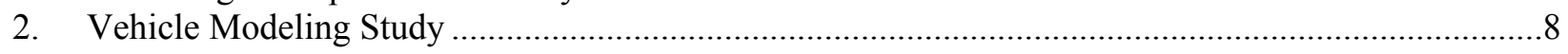

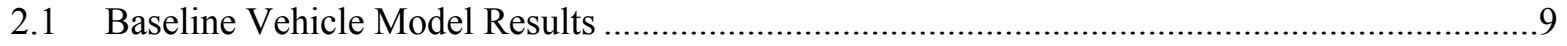

2.2 Fuel EConomy Results for the Advanced Engine and Vehicle ............................................10

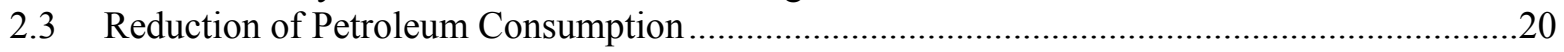

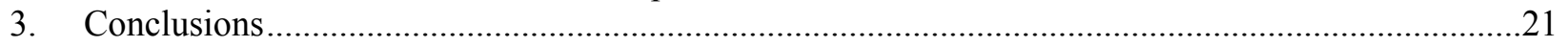




\section{FIGURES}

Figure 1. The GEFORCE matrix of fuels was formulated to explore impacts of RON, ethanol content, and final boiliing point on the fuel economy and emissions of the experimental engine.

Figure 2. Projected energy consumption for the baseline engine and vehicle using Haltermann EEE 97 RON gasoline.

Figure 3. Projected fuel economy results for the baseline engine and vehicle using Haltermann EEE 97 RON gasoline.

Figure 4. Comparison of projected energy consumption values for the baseline engine using EEE gasoline and the advanced engine using fuel $P$.

Figure 5. Comparison of projected fuel economy values for the baseline engine using EEE gasoline and the advanced engine using fuel $\mathrm{P}$.

Figure 6. Projected energy consumption for the advanced engine on the UDDS cycle using the study fuels

Figure 7. Fraction of time spent at each engine condition for the advanced engine using fuel $P$ (left) and fuel L (right) on the UDDS cycle.

Figure 8. Projected fuel economy on the UDDS drive cycle for the advanced engine using the study fuels.

Figure 9. Projected energy consumption for the advanced engine using study fuels on the HWFET cycle.

Figure 10. Fraction of time spent at each operating condition for the HWFET cycle for fuel $P$ (left) and fuel L (right).

Figure 11. Projected fuel economy results for the advanced engine using study fuels on the HWFET cycle.

Figure 12. Projected energy consumption results for the advanced engine using study fuels on the city portion of the US06 cycle.

Figure 13. Comparison of the fraction of time spent at each condition for the city portion of the US06 cycle for fuels P (left) and L (right).

Figure 14. Projected fuel economy results for the advanced engine using the study fuels on the city portion of the US06 cycle.

Figure 15. Projected energy consumption for the advanced engine using study fuels on the highway portion of the US06 cycle.

Figure 16. Comparison of the fraction of time spent at each condition for fuels P (left) and L (right) on the highway portion of the US06 cycle.

Figure 17. Projected fuel economy for the advanced engine using study fuels on the highway portion of the US06 cycle.

Figure 18. Projected impacts to petroleum consumption for the study fuels. Results are based on a weighted average of the drive cycle results that approximates the EPA 5-cycle weighting method. 


\section{EXECUTIVE SUMMARY}

The Gasoline Engine and Fuels Offering Reduced Fuel Consumption and Emissions (GEFORCE) project was proposed in response to the U.S. Department of Energy's Funding Opportunity Announcement 0991 by a team made up of the members of the Coordinating Research Council (CRC) and the research staff at Oak Ridge National Laboratory (ORNL.) The project focused on investigating the potential benefits that might be attained through synergistic use of specific engine technology together with fuels formulated to represent potential directions that high-octane fuels of the future might progress. A stated objective in the DOE FOA was to demonstrate a $25 \%$ reduction in petroleum consumption through optimization of the engine technologies together with a suitable fuel.

An advanced engine was constructed and used with a matrix of research fuels to investigate potential avenues for efficiency improvement. The engine incorporated technologies expected to become mainstream for boosted engines in the next 10 to 20 years. These included increased compression ratio, a two-stage turbocharger, and cooled external exhaust gas recirculation (EGR). The fuel matrix was designed to investigate impacts from research octane number (RON), volumetric ethanol content, and the final boiling point of the fuel. The engine calibration was optimized for each fuel individually and data collected to enable vehicle system modelling that projected energy consumption, fuel economy, tailpipe $\mathrm{CO}_{2}$ emissions, and impact on petroleum consumption for an industry-average mid-size sedan.

The engine calibration and data collection were carried out at IAV in Michigan and is the subject of a separate report. IAV provided the engine data to Oak Ridge National Laboratory to support the vehicle modelling portion of the project.

The vehicle modelling results show the following trends:

- Ethanol content does have a consistently strong influence on the fuel economy results for all cycles and all fuels. Among the fuels of a nominal RON level, increasing ethanol content consistently lowers fuel economy, with the $30 \%$ ethanol fuels always providing the lowest fuel economy for a given RON level. However, in some cases the energy consumption improvement allows the $30 \%$ ethanol fuels to match the fuel economy of the ethanol-free fuel P. These observations underscore the importance of both engine efficiency and fuel volumetric energy content on vehicle fuel economy.

- There was no consistent trend in the projected energy consumption results for differences in fuel T90 for all fuels and cycles. Fuel economy projections did show a consistent trend, with the higher T90 fuel providing slightly greater fuel economy when compared to the low T90 fuel of the same ethanol content. The observed trends were consistent with differences in the heating value of the fuels.

- The 102-RON fuels provided reduced energy consumption and greater fuel economy for the advanced engine on all drive cycles. The engine compression ratio of 11.5 was higher than would typically be used in a turbocharged engine when 92-RON fuel use is expected. Hence, the engine experiences more efficiency degradation from knock avoidance when using the 92-RON fuels. This degradation causes the fuel economy results for the 92-RON fuels to be lower than those for the 102-RON fuels.

- Fuels E and F (92-RON, 30\% ethanol) are projected to achieve $10 \%$ or greater reduction in petroleum consumption, with fuels K (102-RON, 30\% ethanol) and O (97 RON, 30\% ethanol) achieving greater than a $20 \%$ reduction. Fuel L (102-RON, 30\% ethanol) achieves greater than 
$25 \%$ reduction, meeting the petroleum reduction target of the project. All of the fuels that achieve $10 \%$ or greater reduction in petroleum consumption are $30 \%$ ethanol blends.

- Increasing final boiling point increased fuel economy at fixed ethanol content when the 102-RON fuels were used. This trend is a result of differences in the volumetric energy content of the fuels and the projected energy consumption values for the fuels. In the case of the 102-RON fuels, increasing final boiling point also resulted in an increase in the energy content of the fuel. There was not a consistent trend between the energy content and final boiling point for the 92-RON fuels at fixed ethanol content. 


\section{INTRODUCTION}

\subsection{BACKGROUND}

The current state-of-the-art in gasoline engine architecture is the gasoline turbocharged, directinjection engine. Such engines are presently in production but are prevented from achieving even greater efficiency because of the onset of knock, which can irreversibly damage the engine. Techniques for avoiding knock include delaying the ignition timing relative to the piston position, which reduces peak temperatures and pressures in the cylinder and thus removes the knocking condition. Under some conditions where changing ignition timing is insufficient to remove knock, additional fuel is added to cause the combustion conditions to be fuel-rich, which can further cool the in-cylinder conditions. However, the displacement of ignition timing from the thermodynamic optimum location and the use of fuel-rich combustion both degrade the fuel efficiency of the engine. Historically, the onset of knock is most often associated with very high power driving events that occurred infrequently and did not have a significant impact on fuel efficiency. However, the current trend of reducing engine displacement while improving specific power ratings (downsizing) and reducing the engine speeds experienced during most driving modes (downspeeding) are increasing the importance of knock avoidance during a larger portion of typical driving conditions (both on certification cycles and those typical of consumer use). Thus, knock avoidance is rapidly becoming one of the most important limitations to increasing vehicle fuel efficiency.

Ever-tightening emissions regulations have challenged engine designs for many years, and continue to do so. Recent emissions regulations have continued to apply more pressure to reduce emissions, particularly of non-methane organic gas (NMOG) and nitrogen oxides $\left(\mathrm{NO}_{\mathrm{X}}\right)$. Particulate matter (PM) emissions have historically not been problematic for gasoline engines; however, tightening regulatory limits require that direct-injection gasoline engines be designed with more attention to their PM emissions than had been the case with previous gasoline engine architectures, perhaps requiring the use of gasoline particulate filters. Fuel formulation could also play a strong role in PM emissions reductions, since in-cylinder charge motion and fuel injection strategies could benefit from consideration for fuel properties such as the distillation curve, fuel chemistry, density, and viscosity in order to minimize $\mathrm{NMOG}, \mathrm{NO}_{\mathrm{X}}$, and $\mathrm{PM}$ formation during the combustion process. Hence, there is also a strong opportunity to reduce emissions by taking advantage of potential future fuel formulations.

Existing studies have been undertaken to investigate the potential for exhaust gas recirculation (EGR) to aid in both knock avoidance and emissions reduction. Southwest Research Institute's HEDGE consortium, for example, has demonstrated a 10\% brake specific fuel consumption benefit at low loads characteristic of certification cycles using many of the future technologies anticipated to be included in this proposed activity ${ }^{1}$. The HEDGE consortium did not make use of advantageous fuel properties, which can afford additional opportunities for performance optimization leading to further reductions in fuel consumptions, and in some cases direct petroleum displacement. Szybist et al. have shown that inclusion of ethanol in fuel can enable

\footnotetext{
1 “SwRI's HEDGE Technology for High Efficiency, Low Emissions Gasoline Engines," presented at the 2010 DEER Conference by Terry Alger.
} 
additional benefits beyond chemical octane improvement that provides an opportunity for improved ignition timing during knock-limited combustion that further improves brake engine efficiency ${ }^{2}$. Storey et al. showed that inclusion of ethanol in the fuel could provide a significant reduction in PM emissions, and Aikawa et al. showed that the distillation of the fuel, regardless of ethanol inclusion, also plays a significant role in PM formation ${ }^{3,4}$. Similarly, Jung et al. showed that a GTDI engine modified to achieve higher compression ratio could achieve sufficient efficiency improvement in a near-term engine architecture to balance the lower volumetric heating value caused by inclusion of ethanol in the fuel ${ }^{5}$. None of these studies have brought all of these potential interactions between fuel and engine technology together in one designed experiment to assess the simultaneous ranges of both engine technologies and fuel formulations that provide the most joint benefit.

There are a number of future directions that US gasoline formulations could take in response to regulatory requirements, but none of these directions are definitive, and this situation leads to considerable uncertainty in engine and vehicle development as a result. For example, the biofuel mandates promulgated under the Renewable Fuel Standard could lead to increased ethanol content in fuel, but whether this increased content will result in higher octane ratings that can be used to improve fuel efficiency is unknown. PM emissions regulations under the EPA Tier 3 and California LEV III regulations may result in another round of gasoline reformulation to aid in PM reduction, but again the collateral impact on other emissions and fuel efficiency is not clear. Finally, the status quo of gasoline blended with 10\% ethanol to produce an 87-93 anti-knock index (AKI) fuel may continue as these fuels will continue to be useful for the legacy fleet. Future engines will need to provide higher levels of efficiency simultaneously with lower levels of emissions than have ever been achieved, regardless of the direction fuel formulation may take. As has already been discussed, there are opportunities for co-evolution of engine design with gasoline formulation that can enhance efficiency while simultaneously reducing emissions. Identifying the opportunities in self-reinforcing fuel formulation and engine technology could significantly improve opportunities for the OEMs to balance the expectations of customers, manufacturing costs, and national energy and environmental policy objectives. The energy industry (producers, distributors, and retailers) also stands to benefit from this information, as it will identify key fuel formulation directions that are most promising, allowing the industry to subsequently determine the capital improvements that would be needed for changes to fuel formulation towards the proposed solutions.

\footnotetext{
2 "Advantageous Fuel Properties of Ethanol Beyond Octane Number," presented at the 2014 SAE Government/Industry Meeting by Jim Szybist.

3 "Exhaust Particle Characterization for Lean and Stoichiometric DI Vehicles Operating on Ethanol-Gasoline Blends," John M.E. Storey et al., SAE Paper 2012-01-0437.

4 "Development of a Predictive Model for Gasoline Vehicle Particulate Matter Emissions," Koichiro Aikawa et al., SAE Paper 2010-01-2115.

5 "Fuel Economy and CO2 Emissions of Ethanol-Gasoline Blends in a Turbocharged DI Engine," Hosuk Jung, et al., SAE Paper 2013-01-1321.
} 
The Gasoline Engine and Fuels Offering Reduced Fuel Consumption and Emissions (GEFORCE) project was proposed in response to the U.S. Department of Energy's Funding Opportunity Announcement 0991 by a team made up of the members of the Coordinating Research Council (CRC) and the research staff at Oak Ridge National Laboratory (ORNL.) The project focused on investigating the potential benefits that might be attained through synergistic use of specific engine technology together with fuels formulated to

represent potential directions that high-octane fuels of the future might progress. A stated objective in the DOE FOA was to demonstrate a $25 \%$ reduction in petroleum consumption through optimization of the engine technologies together with a suitable fuel. This objective was carried into the project, with a vehicle modeling exercise focused on examining the vehicle fuel economy metric based on data generated using an experimental engine and a matrix of potential future fuel formulations.

\subsection{ENGINE EXPERIMENTAL STUDY}

The largest effort in the GEFORCE project was the assembly and calibration of an engine to include technologies expected to become mainstream in the next 10-20 years using fuels formulated to explore potential fuel formulation pathways that may emerge during a similar timeframe. This work was carried out at GM and at IAV in Michigan and is documented in a companion report. ${ }^{6}$ Some information is repeated here for the convenience of the reader.

The experimental engine was developed with component parts from a GM 2.0-liter LTG and other engines as well as purpose-built components. The swept volume of the engine was increased by replacing the crankshaft with a production model to achieve increased stroke while retaining the bore size and pistons from the original LTG engine. Increasing swept volume in this manner increases compression ratio which in turn is needed to take advantage of fuels with improved anti-knock performance. The swept volume increased from 2.0 to 2.35 liters; the compression ratio increased from 9.5 to 11.5 . Additionally, a high-volume exhaust gas recirculation (EGR) system was added and a two-stage turbocharger system fitted to the engine. These technologies were anticipated to provide flexibility in the engine system to explore potential fuel-related optimization strategies. A production LTG engine was used to provide baseline data against which the performance of the advanced engine could be compared. The baseline data were collected using a premium-grade, ethanol-free certification gasoline (Haltermann Tier 2 EEE) at ORNL.

Staff at IAV performed calibration optimization on the advanced engine using a matrix of fuels formulated to support this project. The fuel matrix was designed to explore the impacts of research octane number (RON), ethanol content (volume \%), and the fuel distillation final boiling point. The fuel matrix is shown in Figure 1. The experimental work at IAV developed fuel consumption and emissions data for the engine for each fuel. These data were developed by operating the engine at a series of speeds from 1,000 RPM to 5,000 RPM and at a range of output up to maximum output torque at each speed.

\footnotetext{
${ }^{6}$ Chi Binh La, Shane Macfarlane, Kevin Sittner, "AVFL-26 Calibration Study on Modified GM LTG Engine Using a Matrix of 15 Fuels," available from the CRC website, www.crcao.org.
} 


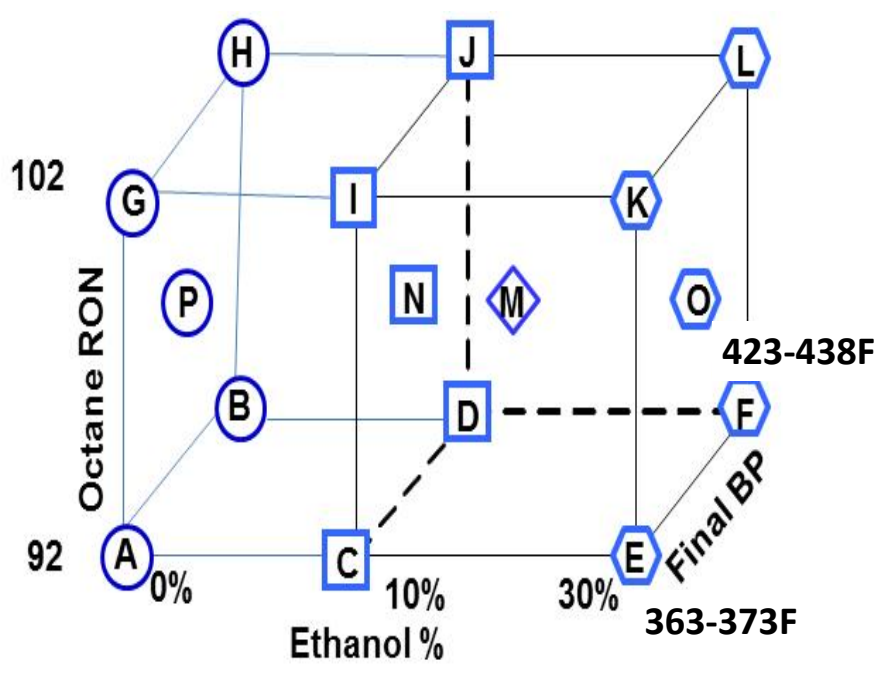

Figure 1. The GEFORCE matrix of fuels was formulated to explore impacts of RON, ethanol content, and final boiliing point on the fuel economy and emissions of the experimental engine. 


\section{VEHICLE MODELING STUDY}

A vehicle modeling study was used to evaluate the engine data developed at IAV to estimate potential impacts on vehicle fuel economy, energy consumption, and tailpipe $\mathrm{CO}_{2}$ emissions. A related study was previously carried out to evaluate these impacts for a near-term gasoline, turbocharged, direct-injection (GTDI) engine using near-term technology in the AVFL-20 project. $^{7}$ The Autonomie simulation package was used to support vehicle modeling in the AVFL-20 project and is also used in the current investigation.

Vehicle modeling investigations were carried out by using an industry-average mid-size sedan as the target vehicle for both the baseline engine and the advanced engine. A detailed description of the development of parameters to describe this vehicle in the Autonomie environment is contained in the AVFL-20 report. The vehicle parameters used in AVFL-20 were carried forward for the current study, with the exception that transmission and final drive ratios were taken from a production vehicle that is equipped with the baseline LTG engine to better match the engine and transmission for the mid-size sedan application. The vehicle model parameters are shown in Table 1.

Table 1. Parameters used in Autonomie to describe the industry-average mid-size sedan.

\begin{tabular}{|l|l|}
\hline \multicolumn{1}{|c|}{ Parameter } & \multicolumn{1}{c|}{ Value } \\
\hline Target Coefficient A (Ibf) & 34.0501 \\
\hline Target Coefficient B (Ibs / MPH) & 0.2061 \\
\hline Target Coefficient C (Ibs / MPH^2) & 0.0178 \\
\hline Equivalent Test Weight (Ibs) & 4000 \\
\hline 1st Gear Ratio & 4.69 \\
\hline 2nd Gear Ratio & 3.31 \\
\hline 3rd Gear Ratio & 3.01 \\
\hline 4th Gear Ratio & 2.44 \\
\hline 5th Gear Ratio & 1.92 \\
\hline 6th Gear Ratio & 1.44 \\
\hline 7th Gear Ratio & 1.00 \\
\hline 8th Gear Ratio & 0.75 \\
\hline 9th Gear Ratio & 0.62 \\
\hline Final Drive Ratio & 2.89 \\
\hline Tire Rolling Radius (m) & 0.32775 \\
\hline
\end{tabular}

As in the AVFL-20 study, the urban dynamometer driving schedule (UDDS), the highway fuel economy test (HWFET), and both the city and highway portions of the US06 driving schedule (US06_city and US06_hwy) were used to investigate vehicle fuel economy, energy consumption, and tailpipe $\mathrm{CO}_{2}$ emissions. The UDDS is the driving schedule used in the U.S. Federal Test Procedure (FTP). The FTP together with the HWFET are used in fuel economy certification calculations in the U.S. The two portions of the more aggressive US06 driving schedule are additionally used in calculation of the 5-cycle fuel economy value that is posted on the window sticker of new vehicles offered for sale.

\footnotetext{
${ }^{7}$ C. Scott Sluder, David E. Smith, Martin Wissink, James E. Anderson, Thomas G. Leone, and Michael H Shelby, "Effects of Octane Number, Sensitivity, Ethanol Content, and Engine Compression Ratio on GTDI Engine Efficiency, Fuel Economy, and CO2 Emissions," AVFL-20 Project Final Report, available from the CRC website, www.crcao.org.
} 


\subsection{BASELINE VEHICLE MODEL RESULTS}

Projected energy consumption results for the baseline engine and vehicle using the Haltermann EEE 97 RON gasoline are shown in Figure 2. Lowest energy consumption occurs for the HWFET cycle; highest energy consumption occurs on the city portion of the US06 cycle. This trend in energy consumption is typical of light-duty vehicles and was also observed in modeling results from the AVFL-20 project. Projected fuel economy values depend on the energy consumption for a given cycle combined with the volumetric energy content for the fuel being used. The projected fuel economy values are shown in Figure 3.

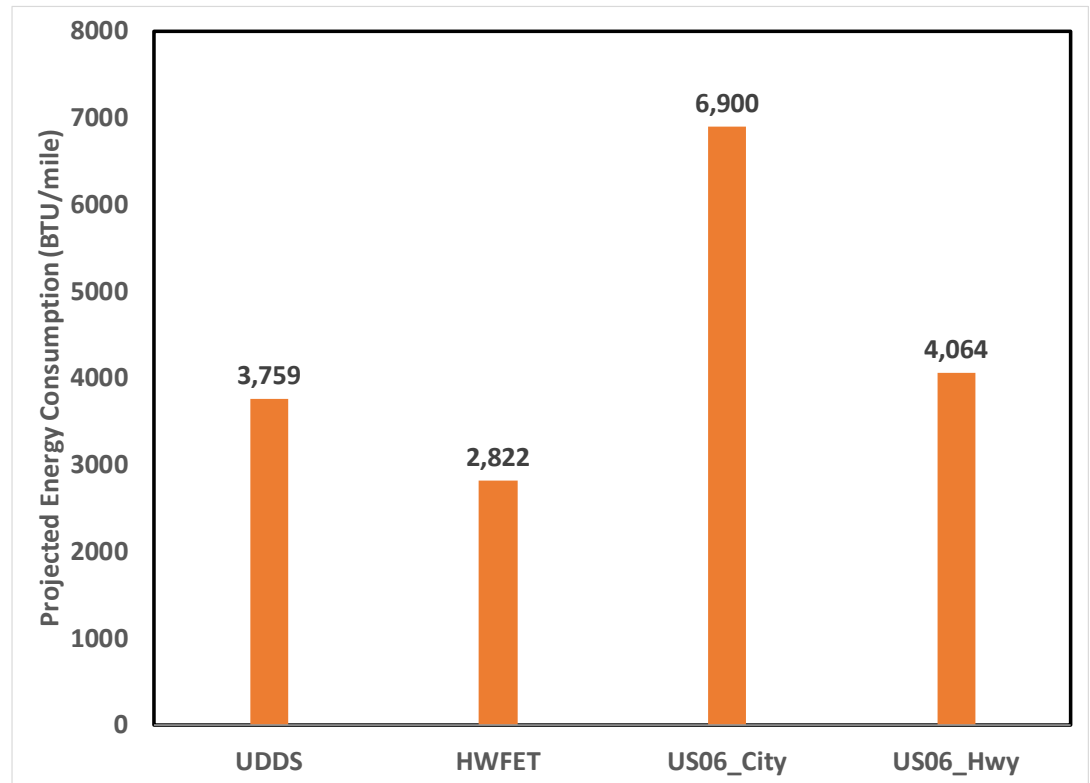

Figure 2. Projected energy consumption for the baseline engine and vehicle using Haltermann EEE 97 RON gasoline.

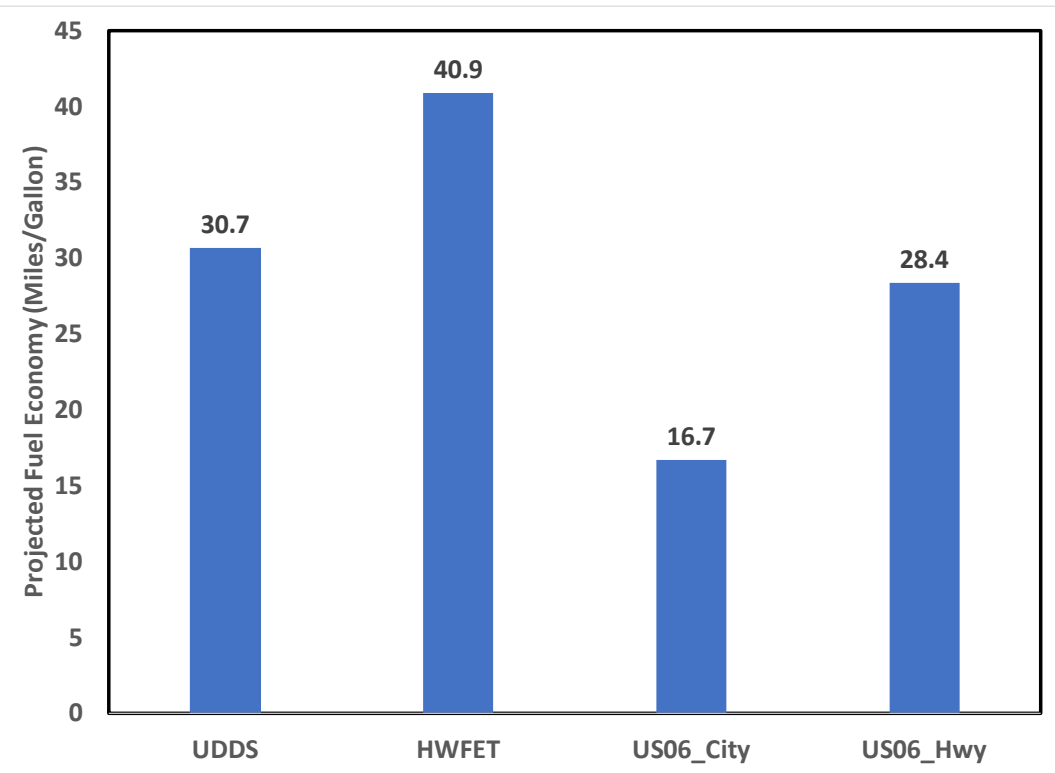

Figure 3. Projected fuel economy results for the baseline engine and vehicle using Haltermann EEE 97 RON gasoline. 


\subsection{FUEL ECONOMY RESULTS FOR THE ADVANCED ENGINE AND VEHICLE}

The advanced engine has a $17.5 \%$ larger displacement than the baseline engine. Comparing this engine using a fuel similar to the fuel used in the baseline engine is a useful comparison to assess differences in energy consumption and fuel economy that may result from the difference in engine displacement. Fuel $\mathrm{P}$ is a $97 \mathrm{RON}$, ethanol-free fuel used in the advanced engine and is therefore similar to the EEE gasoline used in the baseline engine. Comparison of the energy consumption and fuel economy results are shown in Figures 4 and 5.

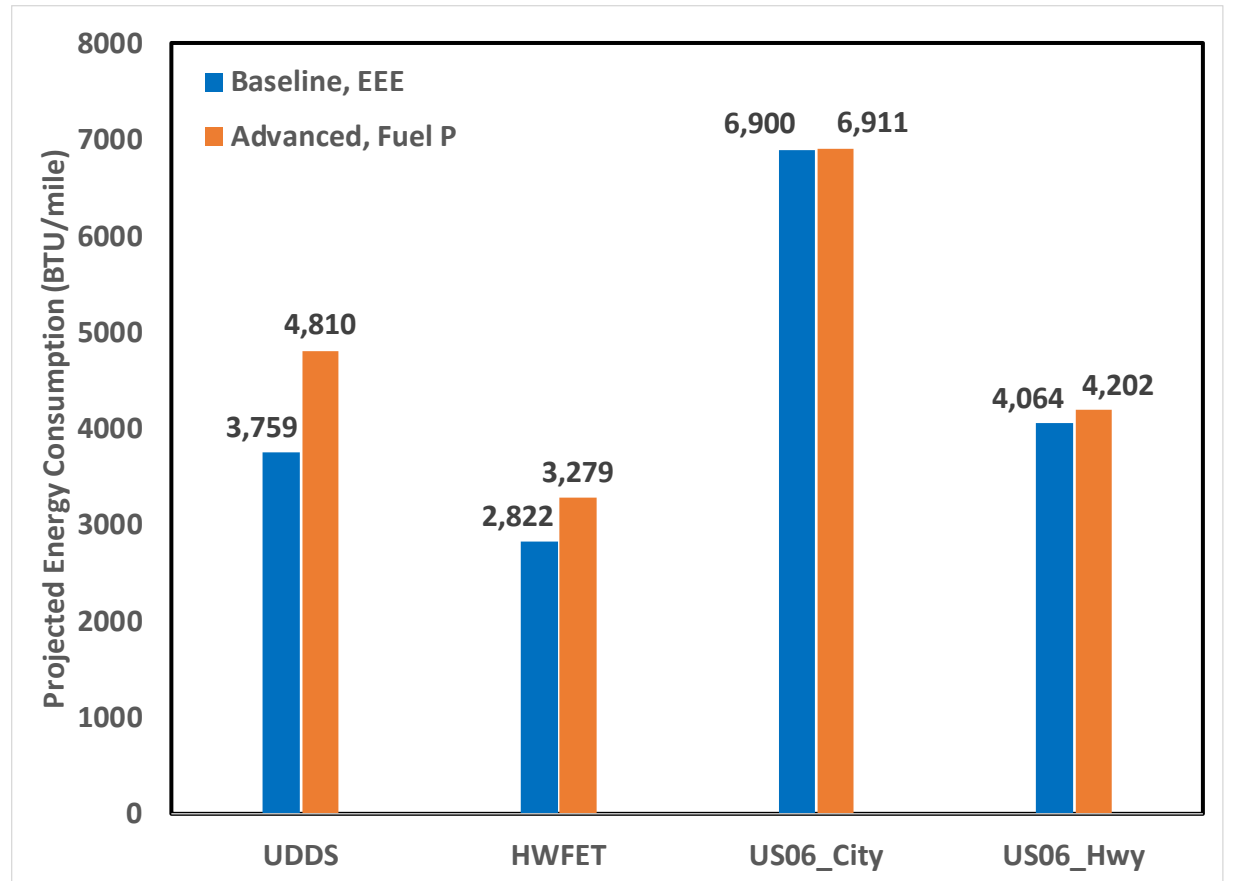

Figure 4. Comparison of projected energy consumption values for the baseline engine using EEE gasoline and the advanced engine using fuel $P$.

The projected energy consumption on a per-mile basis is higher for the advanced engine using fuel $\mathrm{P}$ than for the baseline engine using the EEE fuel on all cycles. This outcome is consistent with a greater degree of throttling loss when the larger displacement engine is used in the same vehicle as the smaller baseline engine. The difference between the two engines is much smaller for the city portion of the US06 cycle, indicating that the advanced engine may be more efficient than the baseline engine at high-load conditions that are more prevalent on this portion of the US06 cycle.

Fuel P has a volumetric energy density of 123,615 BTU/gallon compared with 115,421 for EEE. This difference reduces the mpact of the energy consumption differences noted previously on fuel economy. Nevertheless, for UDDS and HWFET cycles the fuel economy values for the advanced engine are lower than the baseline because of the difference in engine displacement.

Figure 6 shows the projected energy consumption for the UDDS for all the study fuels used in the advanced engine. A broken green line indicates the result achieved with fuel $\mathrm{P}$ for comparison. The 92 and 97 RON fuels (except for fuel O) provide similar energy consumption results. The 102 RON fuels all provide lower (better) energy consumption results. 


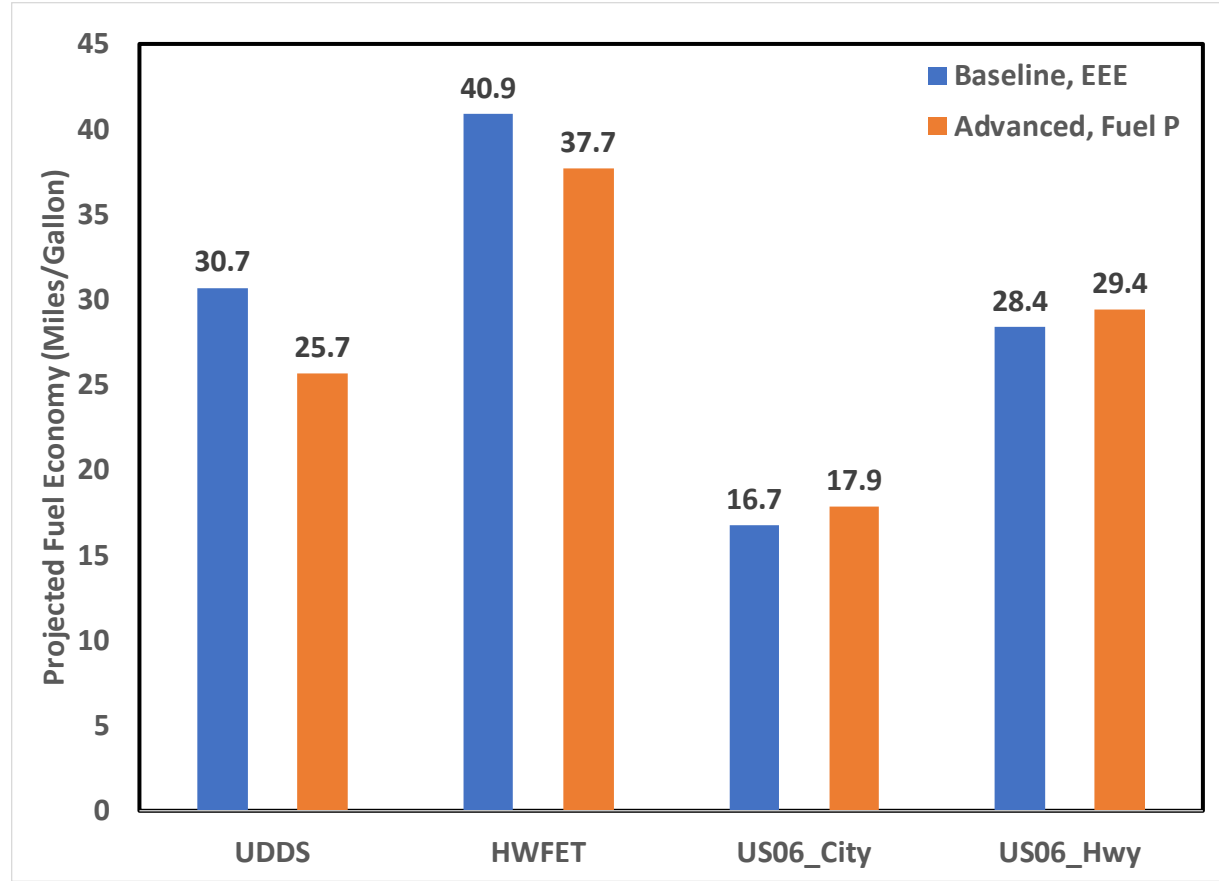

Figure 5. Comparison of projected fuel economy values for the baseline engine using EEE gasoline and the advanced engine using fuel $P$.

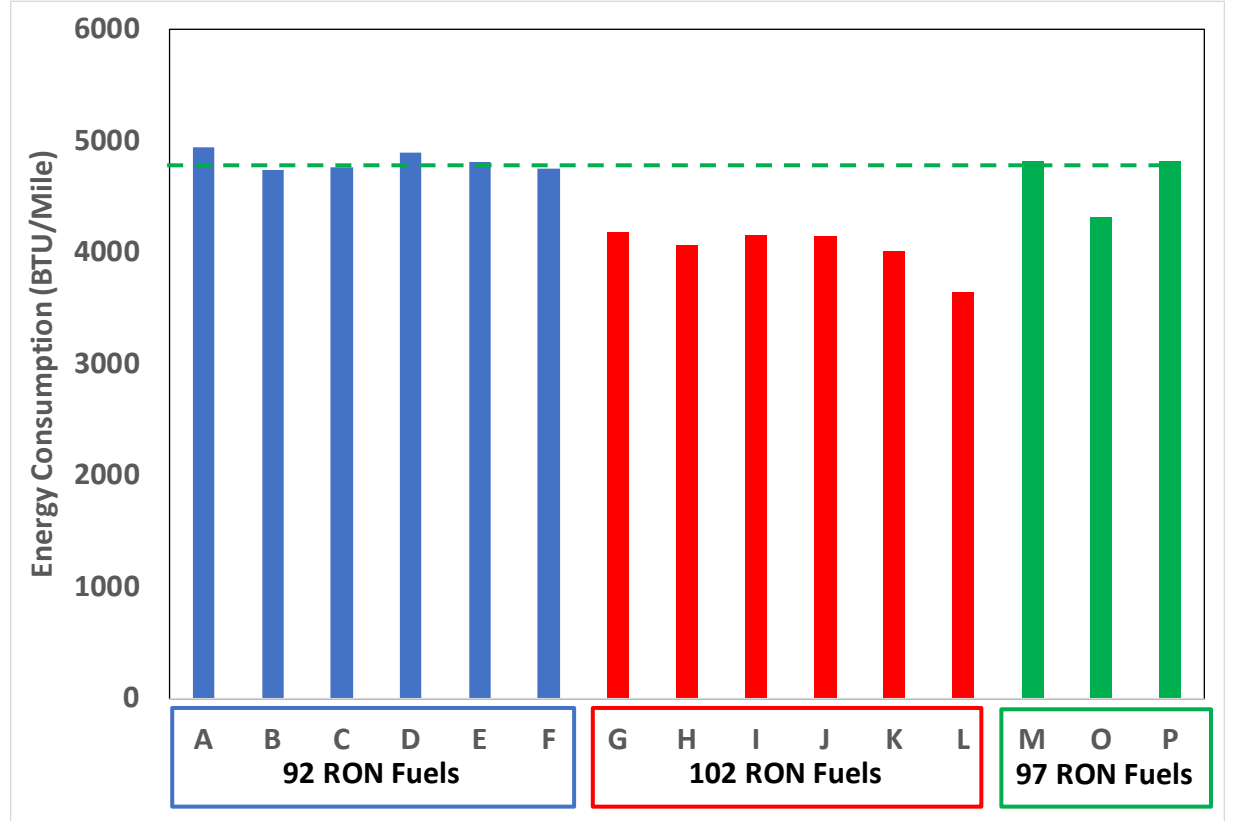

Figure 6. Projected energy consumption for the advanced engine on the UDDS cycle using the study fuels. 
Figure 7 shows the fraction of time spent at each engine operating condition on the UDDS for fuels L and P. The highest concentration of points occurs in very similar locations for the two fuels, but the calibration of the engine for fuel $\mathrm{L}$ causes the efficiency contours to move relative to fuel $\mathrm{P}$. These differences at low output torque values are not likely a result of differing fuel anti-knock properties at low load conditions but are instead more likely an outcome of the overall calibration strategy enabled by the $102-R O N$ fuels. Since the 102-RON fuels span a range of ethanol content, this difference is also not likely a result that is strongly tied to the ethanol content of the fuel

Fuel economy projections for the advanced engine on the UDDS cycle are shown in Figure 8. The lower energy consumption noted for the 102-RON fuels enables them to achieve greater fuel economy than other fuels when evaluated at fixed ethanol content. In fact, Fuel L (a 30\% ethanol fuel) is projected to achieve the same fuel economy as fuel $\mathrm{P}$ (an ethanol-free fuel). This occurrence is noteworthy since ethanol blending reduces fuel volumetric energy content and frequently reduces fuel economy. The remainder of the 97- and 92-RON fuels were projected to provide lower fuel economy than fuel $\mathrm{P}$ on the UDDS.

Figure 9 shows the energy consumption for the advanced engine and study fuels for the HWFET cycle. Figure 10 shows a comparison between the fraction of time spent at each operating condition for the HWFET cycle for fuels L and P. Figure 11 shows the projected fuel economy for the study fuels for the HWFET cycle. Fuels $\mathrm{M}$ and $\mathrm{P}$ exhibit nearly identical energy consumption, with the remainder of the fuels providing lower energy consumption on the HWFET. Comparing the time spent at each condition for fuels $\mathrm{L}$ and $\mathrm{P}$ shows that for these two fuels, the difference in energy consumption is primarily driven by the difference in size and shape of the $35 \%$ efficiency contour of the engine map. The fuel economy results for many fuels still fall below that of fuel P. Four of the six 102-RON fuels (with ethanol content less than 30\%) do provide an improvement in fuel economy relative to fuel P. Fuel L, a $30 \%$ ethanol fuel, provides parity with fuel $\mathrm{P}$ in terms of fuel economy and the lowest energy consumption of any of the fuels on the HWFET cycle.

Figure 12 shows the energy consumption and fuel economy results for the city portion of the US06 cycle. Although the energy consumption levels are higher for the city portion of the US06 than for the UDDS, the trend among the fuels is similar. The $92-\mathrm{RON}$ fuels provide energy consumption results that are comparable to fuel $\mathrm{P}$, with four fuels providing improved energy consumption. All of the 102-RON fuels provide improvements in energy consumption, with fuel L providing the lowest energy consumption. Comparison of the fraction of time spent at each condition for fuels $\mathrm{L}$ and $\mathrm{P}$ on this cycle (Figure 13) shows that the primary driver of improved cycle-average energy efficiency for fuel $\mathrm{L}$ is the size and shape of the $35 \%$ efficiency contour. Figure 14 shows the projected fuel economy for the study fuels for the city portion of the US06 cycle. Two of the 102-RON fuels ( $\mathrm{G}$ and H, both ethanol-free fuels) provide higher fuel economy than fuel P.

Figure 15 shows the energy consumption and fuel economy projections for the highway portion of the US06 cycle. Figure 16 show the comparison of fraction of time spent at each point for fuels $\mathrm{L}$ and $\mathrm{P}$ for the highway portion of the US06 cycle. As noted previously, the size and shape of the $35 \%$ efficiency contour is the prevailing difference between the two engine calibrations.

Figure 17 show the projected fuel economy for the study fuels on the highway portion of the US06 cycle. All fuels except fuel $\mathrm{M}$ offer reduced energy consumption compared to fuel $\mathrm{P}$ on this cycle, with four fuels (G, H,I , and J) simultaneously offering equal or higher fuel economy. Among the 92-RON fuels there does not seem to be a strong overall trend linking ethanol content to energy consumption for all the drive cycles examined. In some cases the $30 \%$ ethanol fuels ( $\mathrm{E}$ and $\mathrm{F}$ ) provide the lowest energy consumption of the $92-\mathrm{RON}$ fuels, but in other cases the greatest benefit is provided by fuel $\mathrm{A}$, a $10 \%$ ethanol fuel. Fuel O consistently provided the lowest energy consumption of the 97-RON fuels, but the 
results from fuels $\mathrm{M}$ and $\mathrm{P}$ don't provide as much consistency. This trend suggests that ethanol content may be a contributor, but is not the only factor in the consistently low energy consumption of fuel $\mathrm{O}$. Fuel $\mathrm{L}$ has the lowest energy consumption, $\mathrm{K}$ is the second lowest, and $\mathrm{G}, \mathrm{H}, \mathrm{I}$, and $\mathrm{J}$ are higher. Although fuel L consistently provided the lowest energy consumption of the 102-RON fuels the results for all the 102-RON fuels do not present a consistent trend with respect to ethanol content. Thus, while ethanol content is perhaps a contributing factor in the energy consumption results of the study fuels, it is not the only fuel formulation characteristic that determines energy consumption for all the cycles.

Ethanol content does have a consistently strong influence on the fuel economy results for all cycles and all fuels. Among the fuels of a nominal RON level, increasing ethanol content consistently lowers fuel economy, with the $30 \%$ ethanol fuels always providing the lowest fuel economy for a given RON level. However, in some cases the energy consumption improvement allows the $30 \%$ ethanol fuels to match the fuel economy of the ethanol-free fuel P. These observations underscore the importance of both engine efficiency and fuel volumetric energy content on vehicle fuel economy.

Similarly, there was no consistent trend in the projected energy consumption results for differences in fuel T90 for all fuels and cycles. Fuel economy projections did show a consistent trend, with the higher T90 fuel providing slightly greater fuel economy when compared to the low T90 fuel of the same ethanol content. The observed trends were consistent with differences in the heating value of the fuels.

The 102-RON fuels provided reduced energy consumption and greater fuel economy for the advanced engine on all drive cycles. The engine compression ratio of 11.5 was higher than would typically be used in a turbocharged engine when $92-\mathrm{RON}$ fuel use is expected. Hence, the engine experiences more efficiency degradation from knock avoidance when using the 92-RON fuels. This degradation causes the fuel economy results for the 92-RON fuels to be lower than those for the 102-RON fuels.

Increasing final boiling point increased fuel economy at fixed ethanol content when the 102-RON fuels were used. This trend is a result of differences in the volumetric energy content of the fuels and the projected energy consumption values for the fuels. In the case of the 102-RON fuels, increasing final boiling point also resulted in an increase in the energy content of the fuel. There was not a consistent trend between the energy content and final boiling point for the 92-RON fuels at fixed ethanol content. 

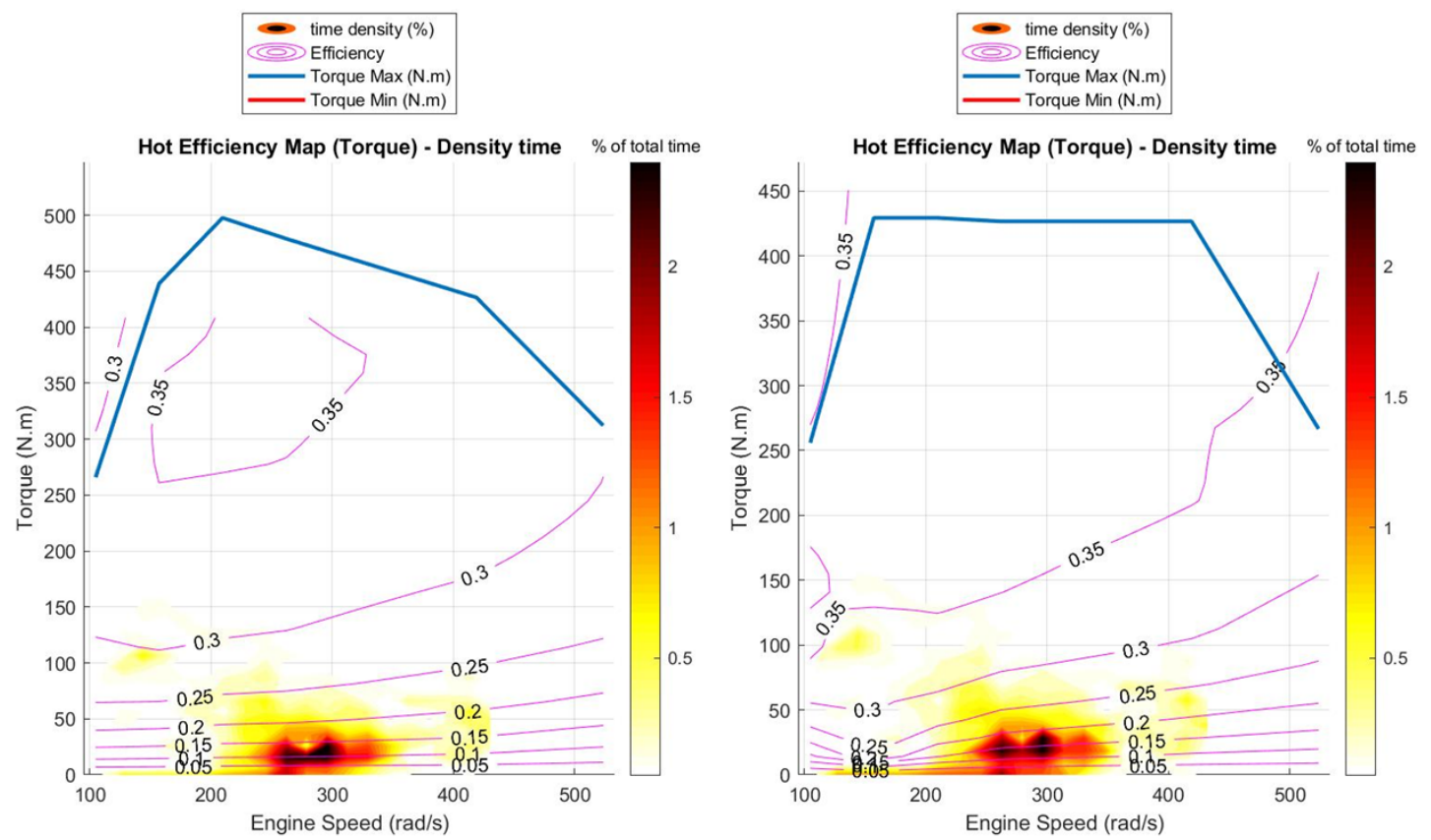

Figure 7. Fraction of time spent at each engine condition for the advanced engine using fuel P (left) and fuel L (right) on the UDDS cycle.

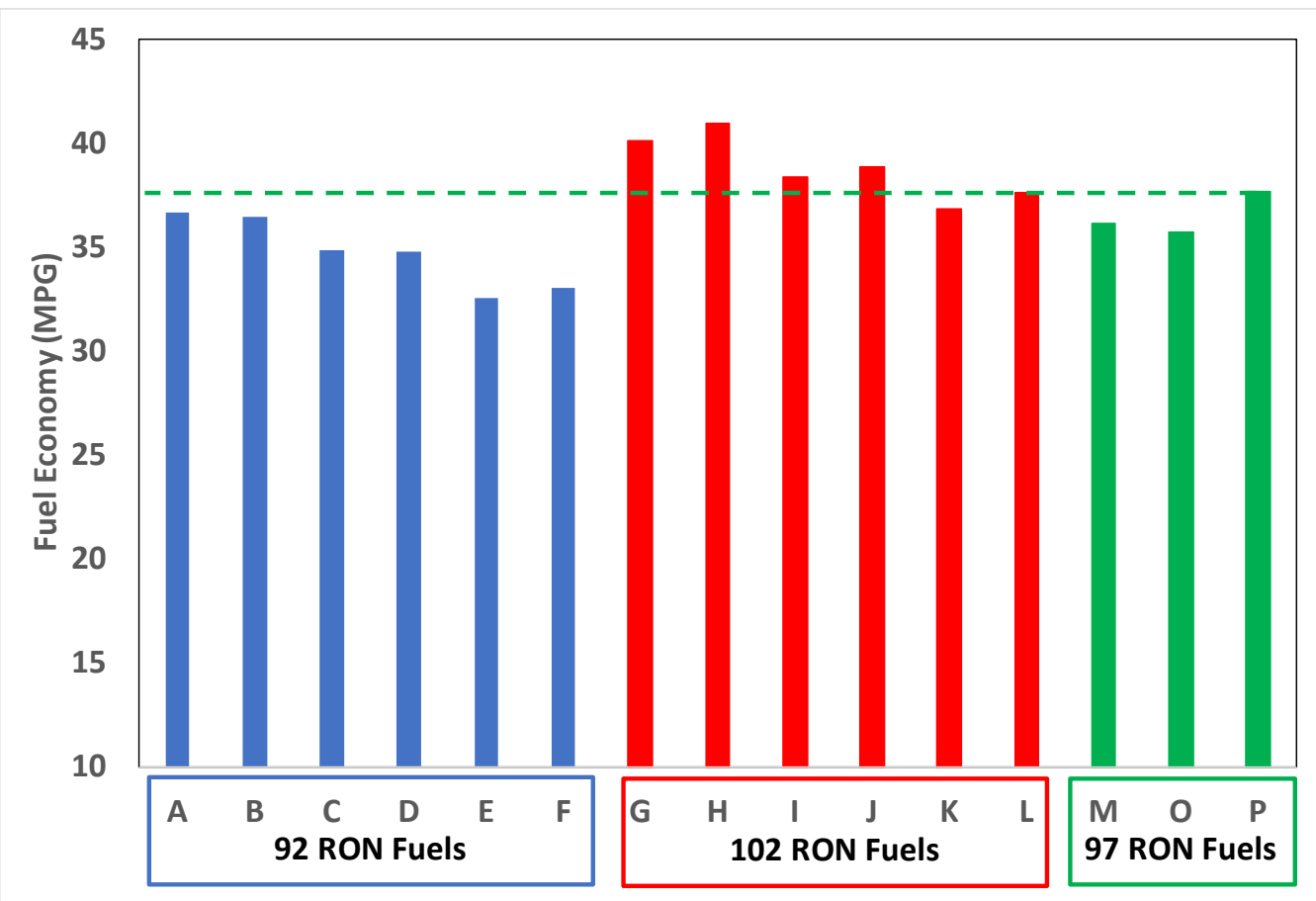

Figure 8. Projected fuel economy on the UDDS drive cycle for the advanced engine using the study fuels. 


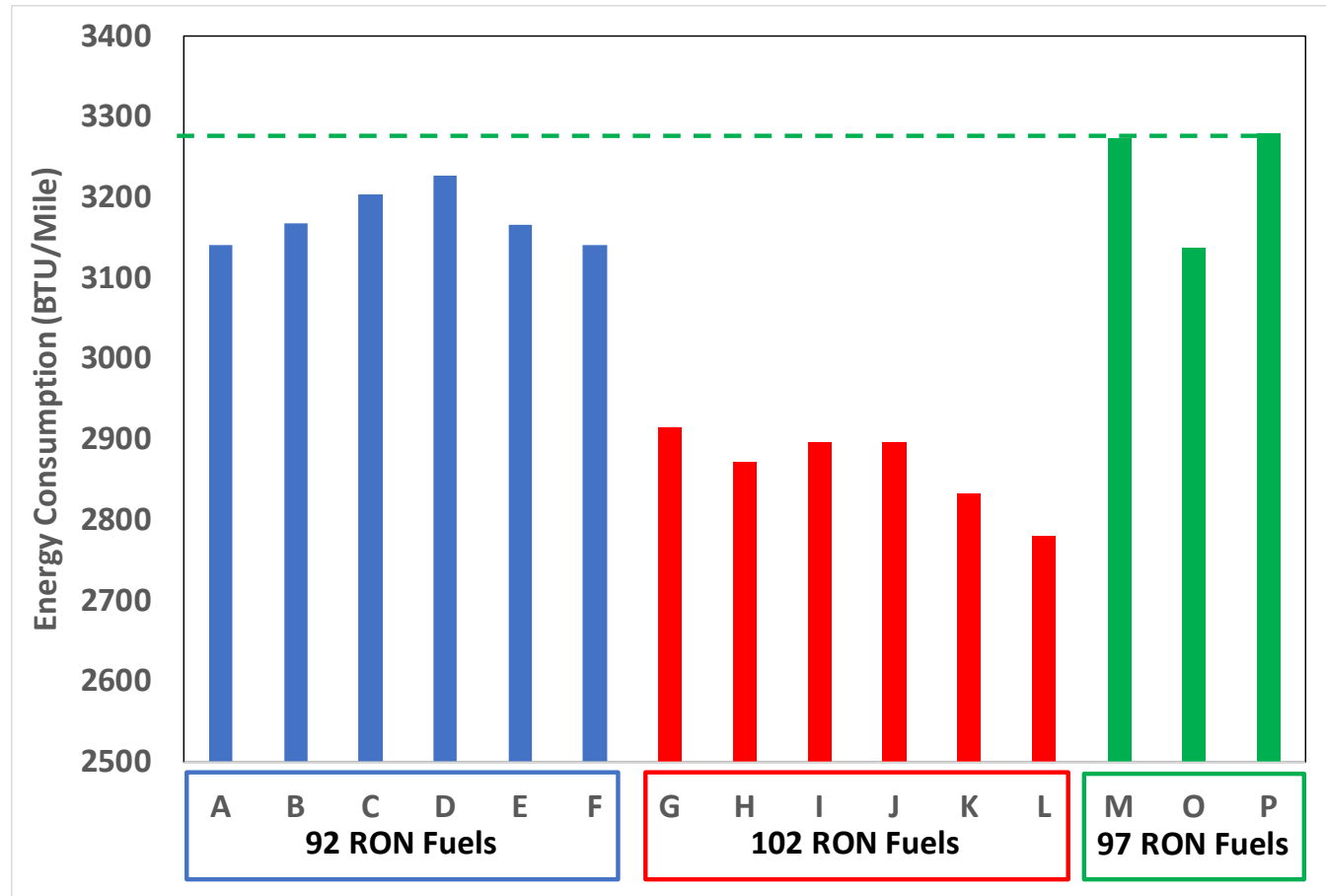

Figure 9. Projected energy consumption for the advanced engine using study fuels on the HWFET cycle.
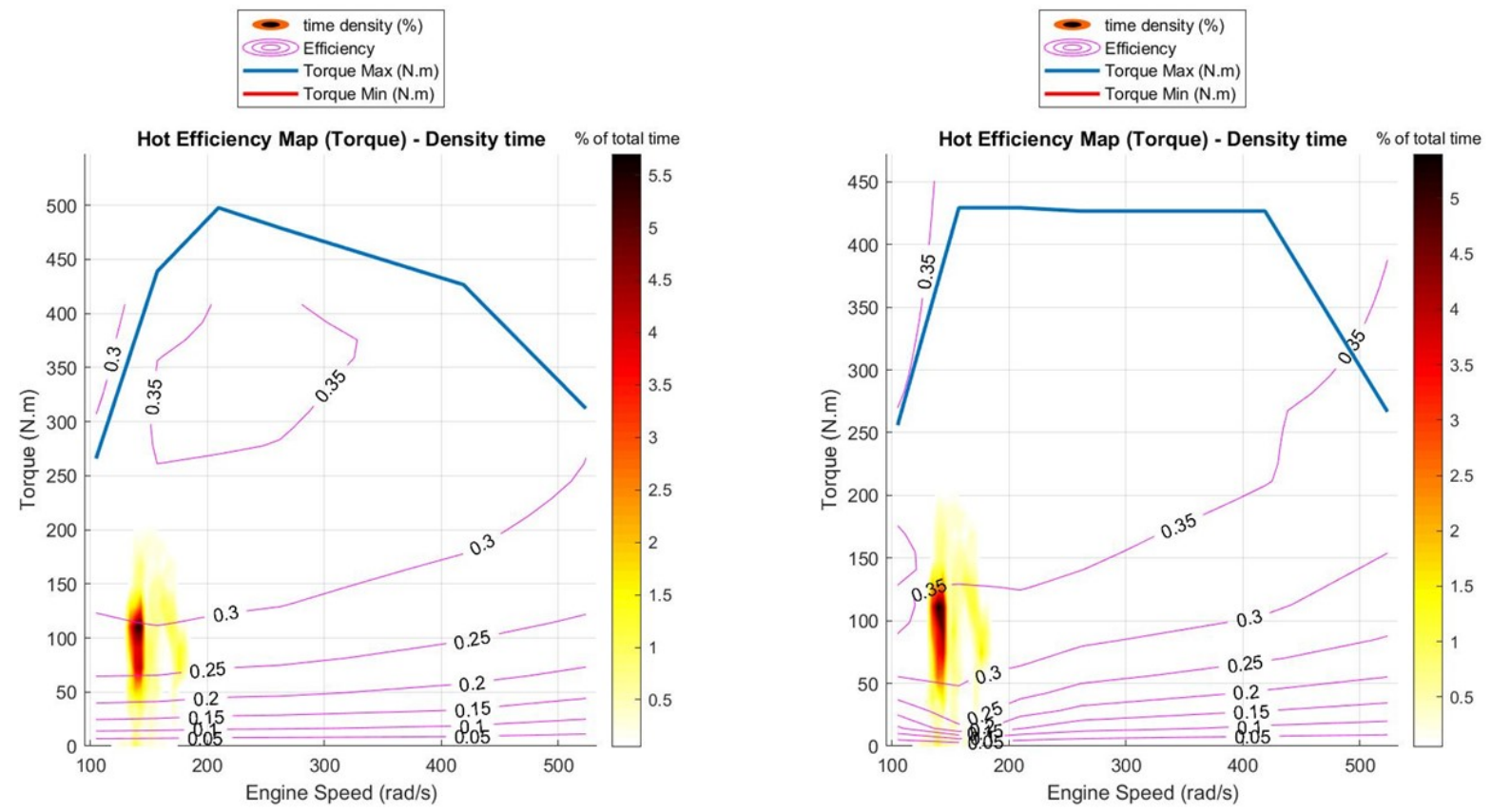

Figure 10. Fraction of time spent at each operating condition for the HWFET cycle for fuel P (left) and fuel L (right). 




Figure 11. Projected fuel economy results for the advanced engine using study fuels on the HWFET cycle.

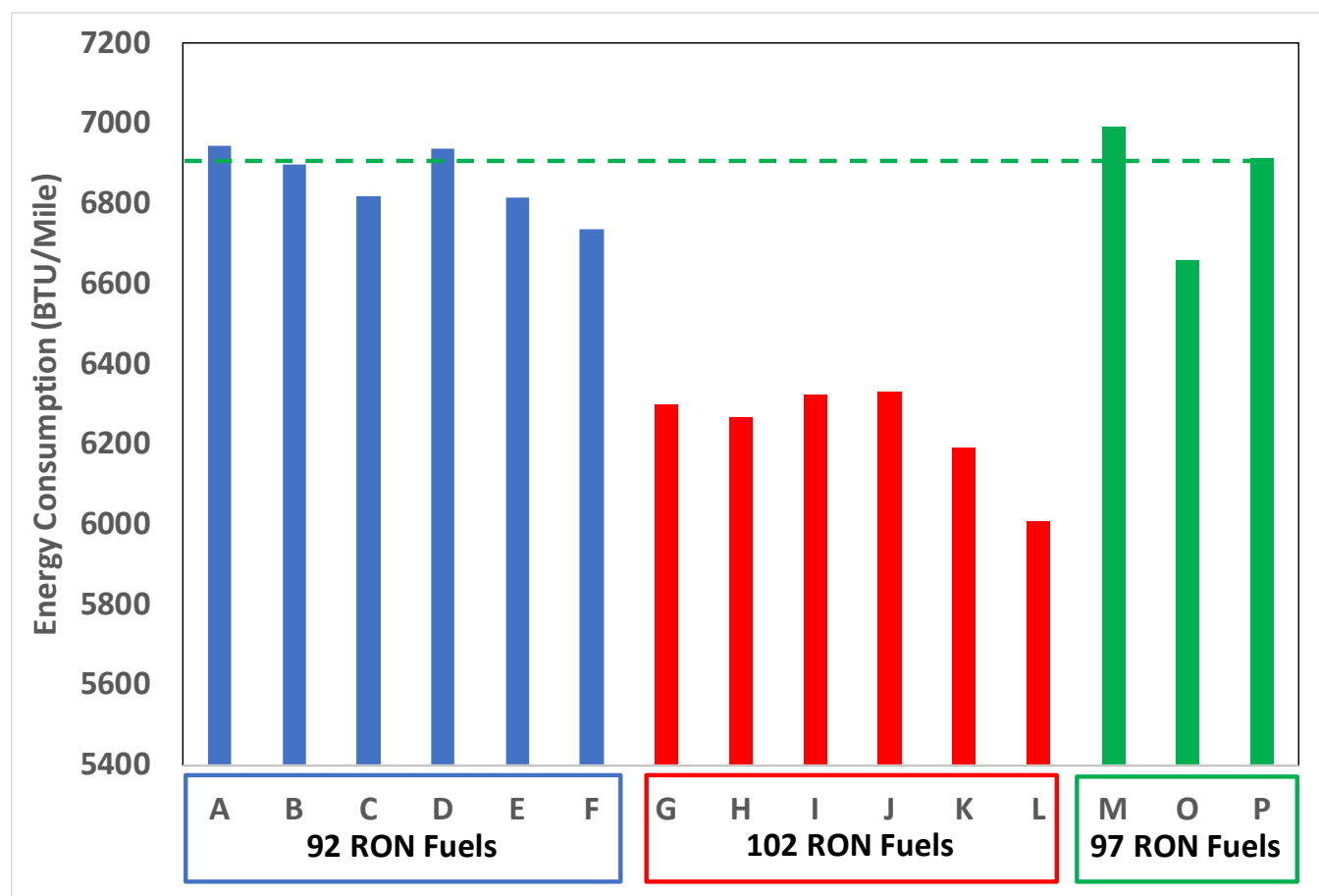

Figure 12. Projected energy consumption results for the advanced engine using study fuels on the city portion of the USO6 cycle. 

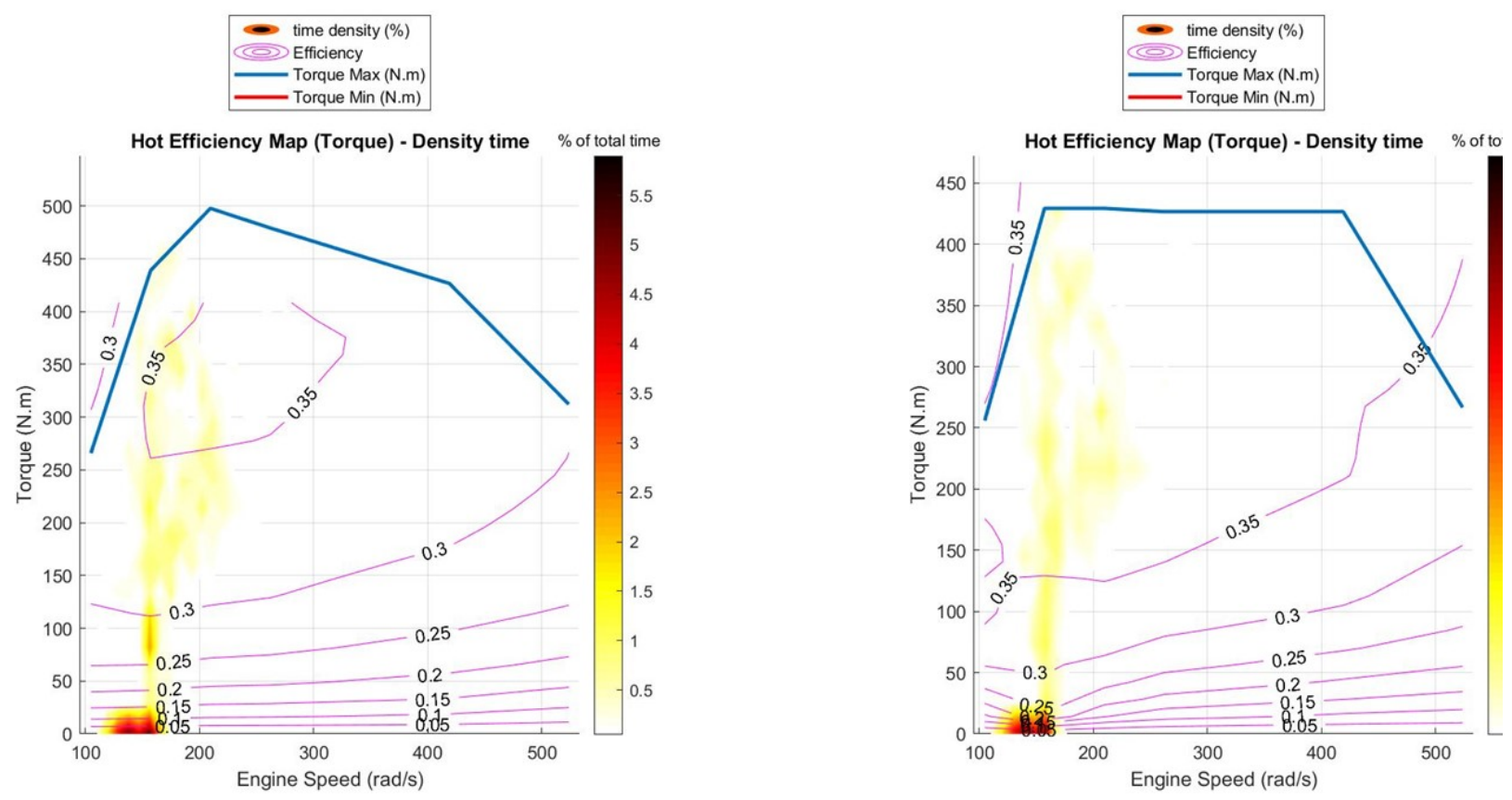

Figure 13. Comparison of the fraction of time spent at each condition for the city portion of the USO6 cycle for fuels $P$ (left) and $L$ (right).

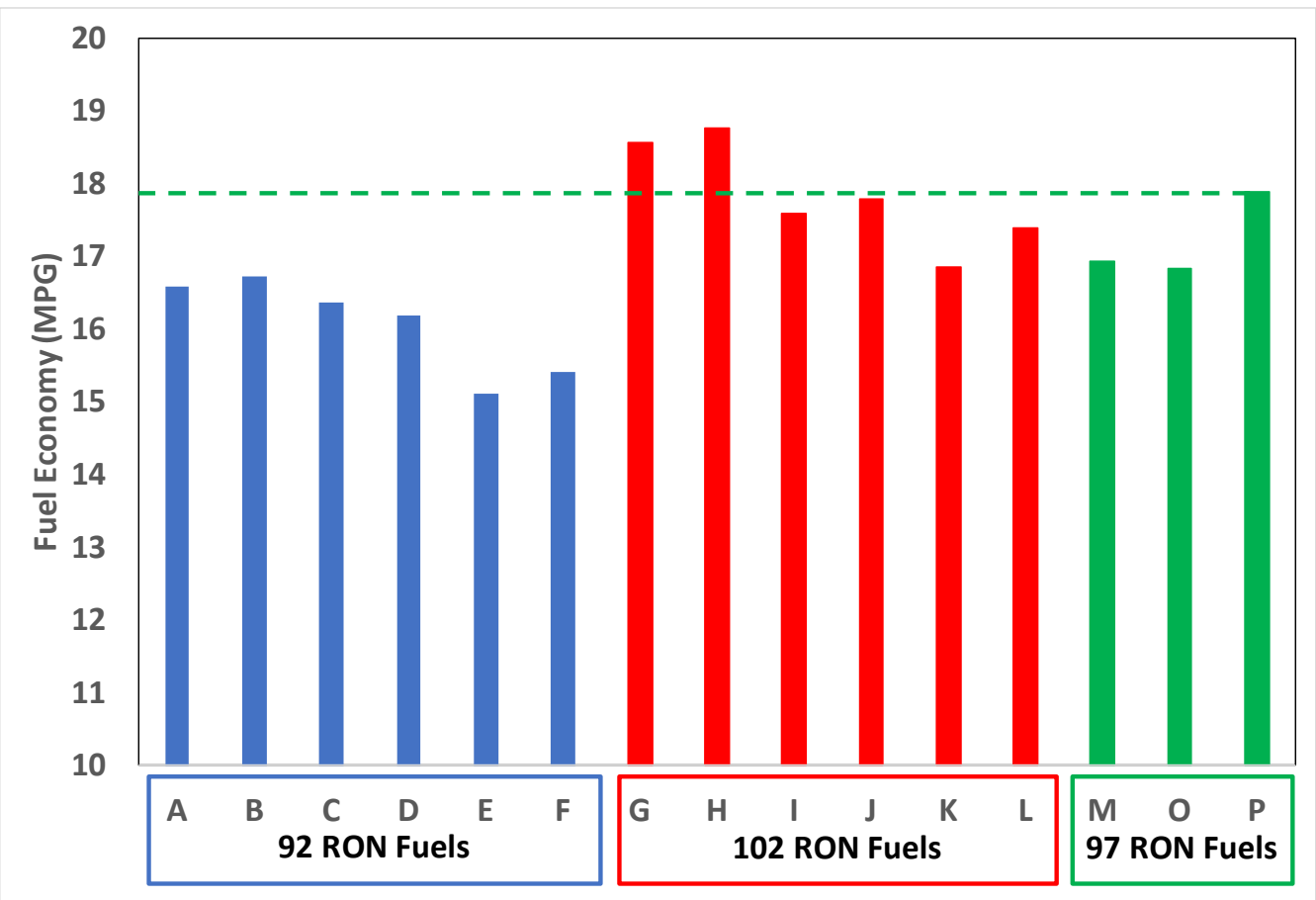

Figure 14. Projected fuel economy results for the advanced engine using the study fuels on the city portion of the US06 cycle. 


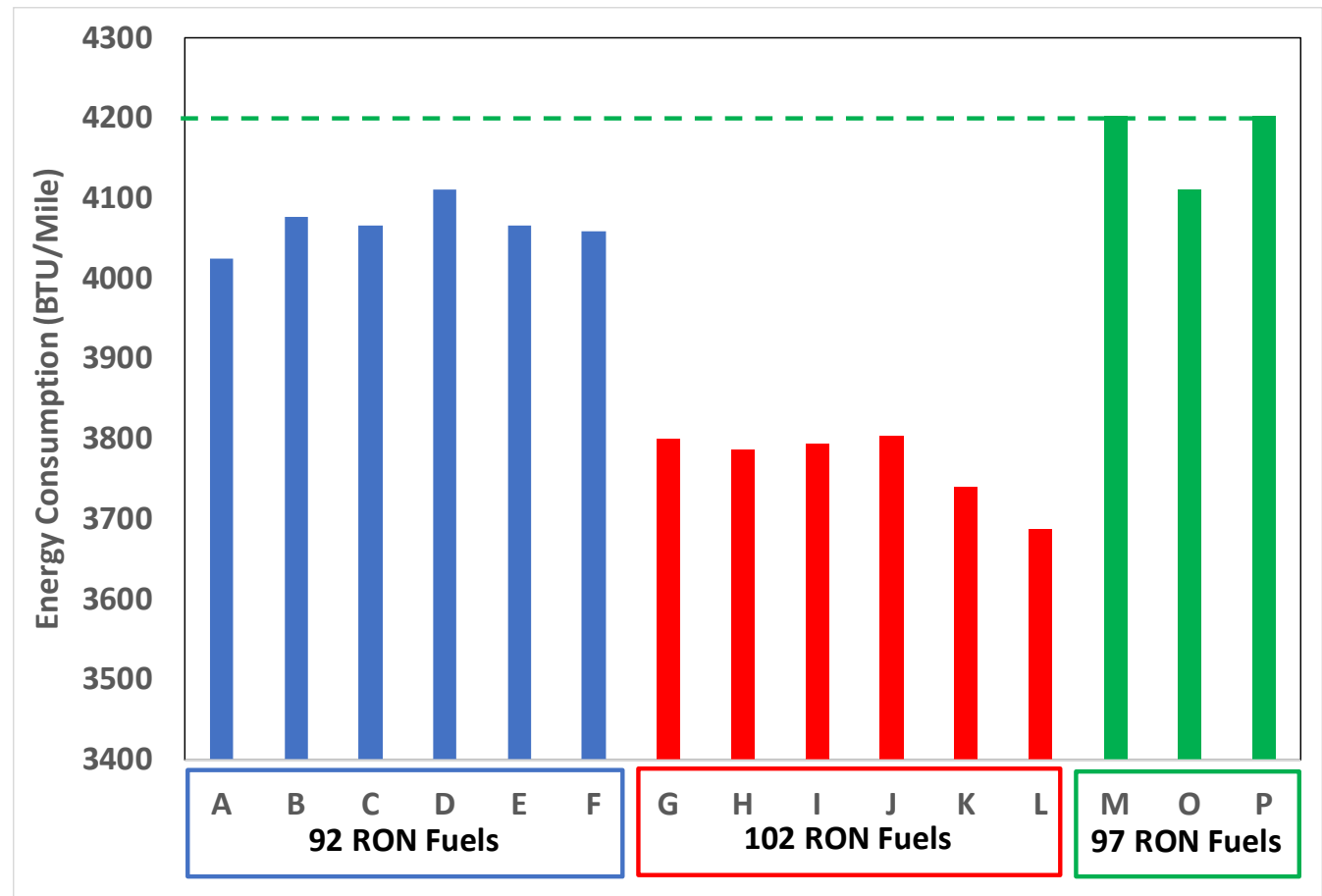

Figure 15. Projected energy consumption for the advanced engine using study fuels on the highway portion of the USO6 cycle.


Figure 16. Comparison of the fraction of time spent at each condition for fuels P (left) and L (right) on the highway portion of the US06 cycle. 


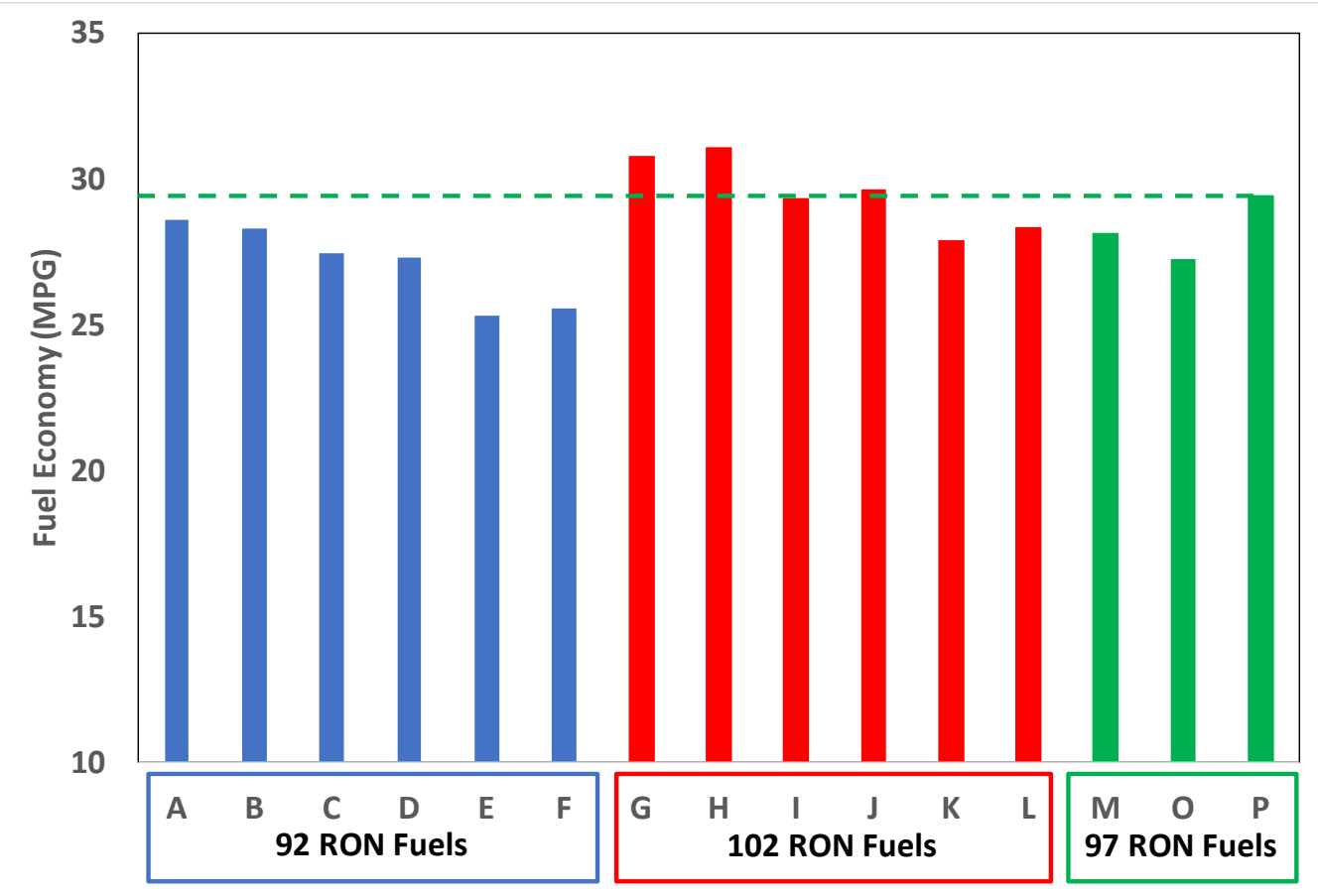

Figure 17. Projected fuel economy for the advanced engine using study fuels on the highway portion of the USO6 cycle. 


\subsection{REDUCTION OF PETROLEUM CONSUMPTION}

A goal of this project was to reduce petroleum consumption by $25 \%$. This objective is most likely to be achieved when the energy consumption for all four cycles is reduced significantly in combination with a substantial biofuel blending. The lower the energy consumption for the cycle can be, the less biofuel blending is needed to achieve the goal, and vice versa. Because the larger displacement advanced engine has higher energy consumption than the baseline engine when similar fuels are used, reductions in petroleum consumption are driven primarily by biofuel blending. Virtually all real-world driving combines aspects of the cycles studied. An approximation of the EPA 5-cycle weighting was used to combine the results of all cycles studied to a single petroleum reduction estimate. The approximation of the 5-cycle weighting used the UDDS results in place of all FTP, Cold CO, and SC03 results as was the case in a related study. ${ }^{8}$ Figure 18 shows the projected impacts to petroleum consumption for all of the study fuels. Fuels $\mathrm{E}$ and $\mathrm{F}$ achieve $10 \%$ or greater reduction in petroleum consumption, with fuels $\mathrm{K}$ and $\mathrm{O}$ achieving greater than a $20 \%$ reduction. Fuel $\mathrm{L}$ achieves greater than $25 \%$ reduction, meeting the petroleum reduction target of the project. All of the fuels that achieve $10 \%$ or greater reduction in petroleum consumption are $30 \%$ ethanol blends.



Figure 18. Projected impacts to petroleum consumption for the study fuels. Results are based on a weighted average of the drive cycle results that approximates the EPA 5-cycle weighting method.

\footnotetext{
${ }^{8}$ C. Scott Sluder, David E. Smith, James E. Anderson, Thomas G. Leon, and Michael H. Shelby, "U.S. DRIVE Fuels Working Group Engine and Vehicle Modeling Study to Support Life-Cycle Analysis of High-Octane Fuels," February 2019. Available on the web at https://www.energy.gov/eere/vehicles/downloads/us-drive-fuels-working-grouphigh-octane-reports
} 


\section{CONCLUSIONS}

- Data collected from calibration of an advanced engine at IAV for a matrix of fuels were used in an Autonomie simulation to project energy consumption and fuel economy results for an industry-average mid-size sedan.

- Use of the larger displacement (2.35L) advanced engine caused the energy consumption of the mid-size sedan to increase relative to the baseline (2.0L) engine on all driving cycles.

- A number of the study fuels enabled reductions in energy consumption for the advanced engine on one or more of the drive cycles compared to the use of Fuel $\mathrm{P}$, which was similar to the EEE fuel used in the baseline engine.

- A 102-RON 30\% ethanol blend, fuel L, was projected to provide the lowest energy consumption on all driving cycles. Fuel L does not provide the highest fuel economy, however, because it has a reduced energy content resulting from its $30 \%$ ethanol content.

- While high levels of ethanol blending often correlated with improvements in energy consumption for the drive cycles studied, the data do not reveal a consistent trend in this regard.

- The 102-RON fuels consistently provided the lowest energy consumption and the highest fuel economy values for the advanced engine on all four cycles.

- Increasing the final boiling point of the fuel at 102-RON resulted in fuel formulations that had increased energy content and thus improved fuel economy relative to fuels with lower final boiling point at the same ethanol content. This trend was not consistent for the 92-RON fuels.

- $25 \%$ reduction in petroleum consumption is projected to be achievable with the advanced engine and fuel L, a 102-RON 30\% ethanol fuel, in mixed driving using a combination of the four drive cycles evaluated in this study. 